\title{
Fatal Case Of Solid Organ Infarcts In a Case Of Myelodysplastic Syndrome (MDS) With Refractory Anaemia
}

\author{
Kolluru Karthik Raja, Yash Gupte, Parth Godhiwala, Sharad Sonawane, Shilpa Gaidhane, Sunil \\ Kumar, and Quazi Syed Zahiruddin.
}

\begin{abstract}
Myelodysplastic syndrome (MDS) usually presents with cytopenias because of bone marrow failure. Solid organ infarcts in myelodysplastic syndrome (MDS) is rarest complication. We report an elderly male, admitted with complaints of pain abdomen mainly in both flanks and swelling all over the body. Peripheral blood smear, bone marrow aspirate for cytology were suggestive of myelodysplastic syndrome(MDS) with refractory anaemia. Fluorescence in situ hybridization(FISH) were negative for any chromosomal abnormalities. His CECT abdomen was done which revealed hepatosplenomegaly with hyperdense liver with multiple splenic and renal infarcts and patient was treated as a case of MDS with refractory anaemia with solid organ infarcts. Over a period of 3 days, he had Acute Kidney Injury (AKI). Patient succumbed on fifth day.
\end{abstract}

Keywords-Myelodysplastic syndrome (MDS), renal infarct, splenic infarct, a case report.

\section{INTRODUCTION}

Myelodysplastic syndrome (MDS) refers to "heterogenous group of bone marrow disorders characterized by clonal hematopoiesis, progressive bone marrow failure, and a propensity to transform into acute myeloid leukaemia (AML)"(1,2). MDS generally presents with anaemia, often with thrombocytopenia and neutropenia. Pathogenic features on bone marrow aspirate shows normal or hypercellular along with dyserythropoietic changes, which is the evidence of ineffective blood production. The complications of MDS are related to cytopenia and the progression to Acute myeloid leukaemia $(1,2)$. Prognosis of MDS is evaluated by IPSS(International Prognostic Scoring System) score which considers cytogenetics, Bone marrow blasts(percent), haemoglobin, platelets and absolute neutrophil count.

Bleeding manifestations in MDS is related to thrombocytopenia and worsened due to platelet dysfunction (3). Acute thromboembolism, which is leads to occlusion of blood supply and causing organ infarction, is rare in patients with MDS. Uptill now, we came across three cases of thrombosis in MDS, one case of cerebral infarct, second case of splenic infarct and third case of Deep vein thrombosis(DVT)(4,5,6). We report a case of MDS presenting with bilateral renal, splenic infarction.

\section{CASE REPORT}

A 63 years old elderly male patient presented with 4 days

Published on May 01, 2020.

Authors are with AVBRH, India.

(corresponding e-mail: drshilpagaidhane@gmail.com) history of pain in abdomen in bilateral flanks, and swelling all over the body. He had no history of constipation or obstipation, haematuria, or oliguria. He had history of receiving multiple blood transfusions in the past. Patient denied past medical history of hypertension, diabetes, coronary artery disease. On examination, he was mesomorphic, febrile, had pulse rate of $112 \mathrm{bpm}$, his Blood pressure was 130/90 $\mathrm{mm} \mathrm{Hg}$. He had severe pallor, pitting oedema feet and periorbital oedema. On abdominal examination, his spleen palpable at $2 \mathrm{~cm}$ below the left coastal margin. There was diffuse tenderness all over the abdomen. Guarding or rigidity over the abdomen was absent.

Laboratory investigations revealed the following values. Haemoglobin $6.2 \mathrm{mg}$ per dL, haematocrit $18.7 \mathrm{mg}$ per dL, Reticulocyte index $0.3 \%$, Platelets $3,45,000 / \mathrm{mm} 3$, WBC count was $8,100 / \mathrm{mm} 3$ with $79 \%$ neutrophils, $2 \%$ eosinophil, $2 \%$ monocyte. His Absolute Neutrophil count was 6399/mm3 Biochemical tests reveals S. Albumin 3.7 gm per $\mathrm{dL}$, Total serum protein $6.5 \mathrm{gm}$ per dL, Aspartate transferase and Alanine transferase were 130 and $108 \mathrm{IU} / \mathrm{L}$ respectively, urea $68 \mathrm{mg}$ per $\mathrm{dL}$, creatinine $0.9 \mathrm{mg}$ per $\mathrm{dL}$, serum $\mathrm{Na}^{+}$ and $\mathrm{K}^{+}$were 130 and 5.2 meq per $\mathrm{L}$ respectively. Urine routine and microscopy showed mild proteinuria. Peripheral smear of blood revealed dimorphic blood picture showing macrocytes with microcytic, mildly hypochromic RBCs with moderate anisopoikilocytosis showing tear drop cells, pencil cells, target cells and occasional tactoid cells. Bone marrow aspirate for cytology revealed hypercellular marrow with erythroid hyperplasia with bilineage dysplasia with dyserythropoietic changes with blast cells of $<2 \%$. His Serum vitamin B12 were $>1000 \mathrm{ng} / \mathrm{ml}$ and S.ferritin levels were $>1000 \mathrm{ng} / \mathrm{ml}$. On Fluorescence in situ hybridization De5q, De7q, De20q, Trisomy 8 were found to be negative. Flow cytometry test for $\mathrm{PNH}(\mathrm{CD} 55, \mathrm{CD} 59)$ revealed normal study. . In view of high B12 with megaloblastic bone marrow, patient was diagnosed as MDS with IPSS score of 3. CECT abdomen was done for determining the cause of abdominal pain. It revealed hepatosplenomegaly with hyperdense liver with multiple splenic and renal infarcts as shown in fig 1 . His $2 \mathrm{DECHO}$ and renal doppler was done to rule out thromboembolism as a cause of splenic and renal infarct. 2DECHO was normal and bilateral renal doppler was normal.

In view of low haemoglobin count, 2 units of packed RBCs were transfused. In view of severe pain in abdomen, Tab morphine was administered for pain relief after ruling out surgical abdomen. Patient was treated with injection meropenem, levofloxacin, injection darbepoetin every 
second week, capsule danazole and other supportive management. Family and patient refused aggressive therapy for MDS. During next 48 hours of hospital stay, he developed renal insufficiency and landed with Acute Kidney Injury. He underwent SLED daily but patient's condition steadily deteriorated. Patient succumbed to his illness on fifth day in hospital.

\section{DISCUSSION}

We present a unique case of bilateral renal and splenic infarct in a MDS- RA. Uptill now, we came across three cases of thrombosis in MDS, one case of DVT, second case of cerebral infarct and third case of splenic infarct $(4,5,6)$. They are summarised in table 1 .

Myelodysplastic syndrome(MDS) is the most commonest haematological disease with an incidence of MDS of around 4 per 1,00,000 population per year(7).MDS presents with signs of hematopoietic insufficiency, particularly symptoms of anaemia, less often susceptibility to infection and bleeding.

Table-1 summarized organ infarction in myelodysplastic syndrome.

\begin{tabular}{lllcll}
\hline $\begin{array}{l}\text { Study } \\
\text { name }\end{array}$ & $\begin{array}{l}\text { No. } \\
\text { of } \\
\text { cases }\end{array}$ & MDS type & $\begin{array}{l}\text { IPSS } \\
\text { score }\end{array}$ & $\begin{array}{l}\text { Site } \\
\text { thrombus }\end{array}$ & $\begin{array}{l}\text { of } \\
\text { Prognosis } \\
\text { (Survived/ } \\
\text { Death) }\end{array}$ \\
\hline Bae et al & 1 & $\begin{array}{l}\text { MDS-RA } \\
\text { with excess } \\
\text { blasts-2 }\end{array}$ & 3 & $\begin{array}{l}\text { Cerebral } \\
\text { infarct }\end{array}$ & $\begin{array}{l}\text { Referred to } \\
\text { higher } \\
\text { centres }\end{array}$ \\
\hline $\begin{array}{l}\text { Nalluru et } \\
\text { al }\end{array}$ & 1 & $\begin{array}{l}\text { Refractory } \\
\text { cytopenia } \\
\text { with } \\
\text { multilineage } \\
\text { dysplasia }\end{array}$ & NA & $\begin{array}{l}\text { Splenic } \\
\text { infarct }\end{array}$ & Survived \\
\hline $\begin{array}{l}\text { Niazy } \\
\text { al }\end{array}$ & 1 & MDS-RA & NA & DVT & Survived \\
\hline $\begin{array}{l}\text { Current } \\
\text { study }\end{array}$ & 1 & MDS-RA & 3 & $\begin{array}{l}\text { Renal } \\
\text { splenic } \\
\text { infarct }\end{array}$ & and \\
\hline \hline
\end{tabular}

*NA-Not Available

Various factors causing renal and splenic infarction were evaluated. The most common causes of renal infarction are thromboembolism from acute myocardial infarction, valvular heart disease, arrhythmias and atheromatous disease. Our patients 2D echo and renal doppler was normal, hence cardioembolic phenomenon was ruled out. On CECT abdomen there is no any evidence of aortic dissection. Multiple blood transfusions and chemotherapy with azacytidine can result in thrombosis. Our patient undergone multiple blood transfusions in the past, which may be the risk factor.

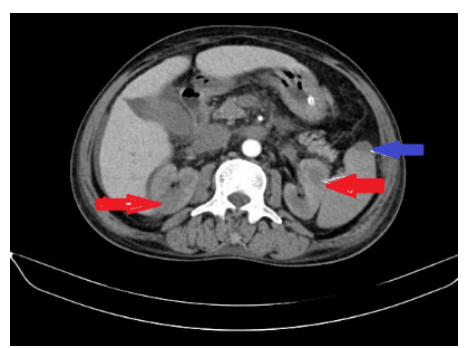

Fig. 1. CECT abdomen reveals bilateral renal infarcts(red arrow) and splenic infarct(blue arrow)

MDS has complex pathogenic features and diversified stages. In early stages of MDS, excessive programmed cell death(apoptosis) is the predominant event with subsequent cytopenia and its variable degree with extent(8). Most of patients with MDS have no apparent cause(approximately $80 \%$ ) and named as idiopathic or primary. Secondary MDS according to WHO develop years after exposure to known agents causing chromosomal damage such chemotherapy (alkylating agents, topoisomerase damage II inhibitors), radiotherapy, heavy metals(mercury, lead), viral infections, toxic chemicals(benzene, fungicide) and autoimmune condition.

MDS is classified by WHO in various subtypes : “i) Refractory anaemia (RA), ii) Refractory anaemia with ringed sideroblasts (RARS), iii) Refractory cytopenia with multilineage dysplasia (RCMD), iv) Refractory cytopenia with multilineage dysplasia and ringed sideroblasts (RCMD), v) Refractory anaemia with excess blasts (RAEB), vi) Myelodysplastic syndrome, unclassified (MDS-U), vii) MDS associated with isolated $\operatorname{del}(5 q)$, viii) chronic myelomonocytic leukaemia(CMML) and Juvenile myelomonocytic leukaemia(JMML)"(9-11).

Peripheral smear in MDS usually reveals Anaemia, either alone or as a part of bi or pancytopenia with macrocytosis with hypogranulated large platelets. Neutrophils are hypogranulated, have hyposegmented, ringed or may contain Dohle bodies. Bone marrow is usually normal or hypercellular with dyserythropoietic changes and ringed sideroblasts in the erythroid lineage, hypogranulation and hyposegmentation in granulocytic precursors with an increase in myeloblasts and megakaryocytes showing reduced number of or disorganized nuclei. In our patient bone marrow revealed hypercellular marrow with erythroid hyperplasia with bilineage dysplasia with dyserythropoietic changes.

The main treatment for MDS is usually supportive care, particularly for symptomatic cytopenias or patients with high risk of infection/bleeding(12,13).Erythropoiesis stimulating agents may improve anaemia. Effective dose of erythropoietin is 60,000 IU/week(14). High-dose darbepoetin has been reported to produce a major erythroid response rate of around $50 \%$ patients $(15,16)$. The use of erythropoietin along with granulocyte colony-stimulating factor(G-CSF) showed good results(17-19). Deferasirox (oral-chelating agent) is widely used in patients with $\operatorname{MDS}(20)$. Response rates to the combination treatment varies with classification. Likely responses are seen in patients with refractory anaemia and ring sideroblasts (RARS) and Responses which are less likely are seen in patients with excess blasts. The international prognostic scoring system(IPSS) is commonly used for risk assessment and therapy initiation. Revised IPSS score is useful to calculate prognosis. IPSS score of our patient is 3. Diseasemodifying agents like Lenalidomide, Immunosuppressive therapy, DNA methyltransferase inhibitors, Acute myeloid leukaemia (AML) Induction type chemotherapy are also in practise. Among all, the only potentially curative treatment for MDS is allogenic Hematopoietic stem cell transplantation(HSCT). Most people with MDS dies due to causes belonging naturally to disease, but not due to progression to AML.

Treatment of renal artery infarcts is unknown. Therapeutic options include: a) systemic anticoagulation 
with dialysis, b) Intraarterial thrombolytic therapy, c)surgical embolectomy(21). The above discussed modalities could not applied to the subject patient as there was small arterial embolization.

\section{CONCLUSION}

Myelodysplastic syndrome presenting with solid infarcts is a rare entity which was the presentation in our patient. Any patient presenting with acute abdomen with myelodysplastic syndrome (MDS) urgent CECT abdomen is helpful for early detection and management of solid organ infarcts.

\section{ACKNOWLEDGEMENT}

The authors would like to thank Dr. Lalith Raut, haematologist for diagnosing this case. We would also like to thank Dr Mallampati Ajit Chakravarthy, Dept of radiology for sharing CECT image with us.

\section{INFORMED CONSENT}

Case report was made after seeking written informed consent from family members.

\section{ETHICAL APPROVAL}

Ethical approval taken from Institutional Ethics committee
[15] Mannone L, Gardin C, Quarre MC, et al.: High dose darbepoetin alpha in the treatment of anemia of lower risk myelodysplastic syndrome results of a phase II study. Br J Haematol 133 (5): 513-9, 2006.

[16] Gabrilove J, Paquette R, Lyons RM, et al.: Phase 2, single-arm trail to evaluate the effectiveness of darbepoetin alfa for correcting anaemia in patients with myelodysplastic syndromes. Br J Haematol 142 (3): 379-93, 2008

[17] Hellstrom-Lindberg E, Ahlgren T, Beguin Y, et al.: Treatment of anemia in myelodysplastic syndromes with granulocyte colonystimulating factor plus erythropoietin: results from a randomized phase II study and long-term follow-up of 71 patients. Blood 92 (1): $68-75,1998$.

[18] Hellstrom-Lindberg E, Kanter-Lewensohn L, Ost A: Morphological changes and apoptosis in bone marrow from patients with myelodysplastic syndromes treated with granulocyte-CSF and erythropoietin. Leuk res 21 (5): 415-25, 1997.

[19] Negrin RS, Stein R, Doherty K, et al.: Maintenance treatment of the anaemia of myelodysplastic syndromes with recombinant human granulocyte colony-stimulating factor and erythropoietin: evidence for in vivo synergy. Blood 87 (10) 4076-81, 1996.

[20] GreenbergPL, Rigsby CK, Stone RM, et al.: NCCN Task Force: Transfusion and iron overload in patients with myelodysplastic syndromes. J Natl Compr Canc Netw 7 (suppl 9): S1-16, 2009.

[21] Neukirchen J, Schoonen WM, Strupp C, et al. Incidence and prevalence of myelodysplastic syndromes: Data from the Dusseldorf MDS-registry. Leuk Res.2011;35:1591-1596.

\section{Author details-}

Kolluru Karthik Raja ${ }^{1}$, Yash Gupte ${ }^{1}$,Parth Godhiwala ${ }^{1}$, Sharad Sonawane ${ }^{1}$, Shilpa Gaidhane ${ }^{2}$, Sunil Kumar', Quazi Syed Zahiruddin ${ }^{3}$.

1.Junior Resident, Department of Internal Medicine, AVBRH, India.

2.Professor, Department of internal medicine, AVBRH, India.

3.Professor, Department of Community Medicine, AVBRH, India.

\section{REFERENCES}

[1] Dansey R. Myelodysplasia. Curr. Opin. Oncol. 2000; 12: 13-21 [Crossref], [PubMed], [Web of Science $\left.{ }^{\circledR}\right]$, [Google Scholar]

[2] Lowenthal R.M., Marsden K.A. Myelodysplastic syndromes. Int. J. Hematol. 1997; 65: 319-338 [Crossref], [PubMed], [Web of Science ®], [Google Scholar]

[3] Mittelman M., Zeidman A. Platelet function in myelodysplastic syndromes. Int. J. Hematol. 2000; 71: 95-98 [Google Scholar]

[4] Swarna Sri Nalluru, Vishal Jindal, Paramarajan Piranavan, Yugandhara Kate, and Ahmad D. Siddiqui, Splenic infarction secondary to myelodysplastic syndrome: unravelling more etiologies.

[5] Hyun Woo Bae, Hyun Dong Kim, Sung Won Choi, Nami Han, Mi Ja Eom, Acute Cerebral Infarction as a Rare Thrombotic Event in Myelodysplastic Syndrome: A Case Report.

[6] MN Niazy*, TI Neyyarapally**, A Chattopadhyay***ErythropoietinInduced Deep Vein Thrombosis in Myelodysplastic Syndrome.

[7] Wurthner, J.U.;kohler,G.;Behringer, D.;Lindemann, A.; Mertelsmann, R.;Lubbert, M. Leukostasis followed by haemorrhage complicating the initation of chemotherapy in patients with acute myeloid leukemia and hyperleukocytosis. Cancer 1999,85, 368-374

[8] Sloand EM, Kim S, Fuhrer M, et al. Fas-mediated apoptosis is important in regulating cell replication and death in trisomy 8 hematopoietic cells but not in cells with other cytogenetic abnormalities. Blood. 2002;100:4427-4432. [PubMed] [Google Scholar]

[9] Labardini JR, Hernández MC, Cervera E, et al., "Síndromes mielodisplásicos". Instituto Nacional de Cancerología, vol.6: 129-32, 2011.

[10] De La Mora O, Guerrero S, García V, et al., "Guia de practica clinica diagnóstico y tratamiento de sindrome mielodisplásico". Catálogo maestro de GPC, Mëxico: 2010

[11] Pintos EN, Carbejo MdR, "Clasificación de los síndromes mielodisplásicos”. Hematología, vol.14, no.3: 86-90, 2010

[12] Tricot GJ, Lauer RC, Appelbaum FR, et al.: Management of the myelodysplastic syndromes. Semin Oncol 14 (4): 444-53, 1987.

[13] Boogaerts MA: Progress in the therapy of myelodysplastic syndromes. Blut 58 (6): 265-70, 1989.

[14] Park S, Grabar S, Kelaidi C, et al.: Predictive factors of response and survival in myelodysplastic syndrome treated with erythropoietin and GCSF: the GFM experience. Blood 111 (2):574-82, 2008. 